\title{
Analysis of Foreignization and Domestication in Translation Strategy from Cross-cultural Perspective
}

\author{
Yu Yang \\ Modern City Management Department, City University of Zhengzhou, 452370
}

Keywords: Domestication, foreignization, cross-cultural translation, post-colonialism

\begin{abstract}
For many years, There are lots of discussions about translation foreignization and domestication, often appeared in the domestic various foreign language journals. Chinese Translators Journal , the fifth issue of 2002 also devoted a column to discuss this issue, which greatly promoted the "domestication" and "alienation" of research, but it is more a stay in the level of language research, from the cross-cultural perspective to explore the phenomena of alienation in literary translation.
\end{abstract}

\section{Quoting}

Recently, Foreign Language Class Journal published many articles about domestication and foreignization, these articles efforts will be in the western literary criticism and comparative literature theory about domestication and foreignization discussion used in translation theory and practice, in some sense, literal translation and free translation from the Angle of culture to make a summary, some articles apply relevance theory to seek domestication and foreignization the optimal relevance point, these articles from different angles to broaden the research of alienation and domestication. But the discussion of domestication and foreignization translation is wrong, the most obvious is the equivalent of literal translation and free translation, domestication and foreignization translation strategy to literature and cultural ideology with the strategy of language and translation skills, which will be discussion of domestication and foreignization back to tradition and experience are discussed, do so incompatible with the development of domestication and foreignization translation studies. "Translation in China" in 2002 the fifth period teleconference with school piano and other articles, discusses the English translation of "domestication" and "alienation" of the research direction and the existing problems, is the new research results of domestication and foreignization translation. This paper will discuss the domestication and foreignization of translation from the perspective of cross-cultural perspective.

\section{One. The word "literal translation" and "paraphrase"}

Literal translation and free translation are the source of the discussion of domestication and alienation, and many scholars often put them together to discuss. Mr. Wang in the "domestication and foreignization: The collision of the conflicts" has made a more in-depth discussion on them. The author points out that "the dispute between domestication and foreignization is an extension of the argument between literal translation and free translation." But he didn't put them together simply, but pointed out: "domestication and foreignization can be seen as an extension of the concept of literal translation and free translation, but not completely equal to literal translation and free translation.... if the literal translation and free translation is the language level of discussion, so, domestication and foreignization is the continuation of upgraded to culture, language level discussion poetics and political level. That is to say, the literal translation and free translation of the bull's-eye meaning and form of gain and loss, and the bull's-eye of alienation and domestication is gain and loss of the cultural identity in meaning and form, and literature and even the loss of discourse right." In view of this view, the foreignization and domestication of literal translation and free translation add a little perspective. When it comes to literal translation and free translation, 
people often use literal translation and free translation in English. At this time, people are concerned about the technical processing problem of the language level, namely how to keep the original form and not distort its meaning. However, the translation thinks that language has different cultural connotations and forms of expression. When the form becomes an obstacle of translation, it is necessary to translate. There are also some people who come up with the idea of conformation and conformation to be symmetrical with literal translation and free translation. Evaluation in China, in favor of literal translation and free translation are someone is, the early Buddhist scripture translation of the article said, Tangxuanzang "truth" and "common" yu, modern is Yan fu's "Elegant writing and Lu xun's" letter "and not" and zhao "ninh thuan without the letter" of depth of field, etc., from the perspective of literal translation and free translation to discuss the principle of translation.

In fact, there is no objection to the translation and translation of literal translation and free translation into a discussion, but we should pay attention to the similarities and differences between them. In the past, domestication/foreignization translation has been discussed more closely with the similarity of literal/literal translation, but the differences between them have not been fully discussed. The two main methods of translation, translation and translation, are not repulsion; instead, they are complementary. In the same translation, both literal and paraphrase may be. The style also has the relation, in some style, the translation will be more, and in the other style, the literal might be more. In the discussion of literal translation and free translation, the translation industry has basically reached consensus. Literal translation and free translation are not the same as those of some people. Lu xun and his younger brother Zhouzuoren's literal translation of "the collection of foreign novels" has attracted many critics and is regarded as a literal translation. Some scholars talked about lu xun, and he would mention that his translation had been "unbelieving" and ignored others. In fact, lu xun about the true meaning of literal translation is he in the and dielectric pavilion essay 2 sets of "topic in the grass," said: "every translation, must give attention to both sides, a strive for its easy solution, of course, a to maintain the original outline." It can be seen that Lu xun is not shun shun, only when the two cannot have both, only to take the letter and shun shun. Lu xun's "hard translation", is by no means blind imitation, also not be translated word by word, but at the same time of introducing foreign progressive literature, trying to enter the new ways to enrich Chinese syntax and vocabulary. The "easy solution" and "fengzi" are the true meaning of lu xun's literal translation. Zhouzuoren in his 1925 "gyro sequence" mentioned: "I still believe that the literal translation, because I think there is no better way. But the literal translation also has the condition, is a must, to the best of Chinese power range, preserve the original style, show the meaning of the primitive, in other words is the letter with." What kind of translation is death and translation? Zhou zuoren used two interesting examples. If you lie on his back, you may lie on his back. Of course, we have a chance to see a few discussions of translation and translation today, but there are few new people.

The domesticating translation and foreignizing translation was proposed in 1995 by American scholar L.Venuti, a term directly derived from a paper presented by German scholar Schleiermacher1813 in 1813. Schleiermacher emphasizes the inseparable relationship between translation and understanding, and points out that there are two situations in translation. One is to get the reader closer to the author, and the other is to get the author closer to the reader. If the reader is close to the author's context, he can feel the exotic atmosphere. Here, Schleiermacher USES the word foreign. According to the above two kinds of translation, Schleiermacher proposed by the author as the center of the translation and translation for the center with readers, it broke through the traditional boundaries of the literal translation and free translation, a great influence on the later scholars, foreignization and domestication of Venuti view clearly inspired by Schleiermacher theory. However, Schleiermacher's theory was based on hermeneutics of Germany, while Venuti was able to put Schleiermacher's argument in the context of the post-colonial context, thus resulting in the translation of foreignization.

Venuti with alienation translation, look at him in the book translation and a paragraph, he is very appreciate salt brown's words: "translation is a game of pure differences: always involves the difference, also hide differences, occasionally showing differences again at the same time, often 
highlight differences. Even so, the translation itself is the difference between alive." In his view, the differences in the translation of weakened for two reasons: first, for a long time, the discussion of translation are covered, it in the value of the target coordinates system in a marginalized position, difference rather than practice, it is in the process of melting. Secondly, the value standard of English and English has formed a global advantage after the war, thus establishing the context of Anglo-American culture. This kind of context only accepts the foreign language text that accords with the ideology of British and American culture in ideology. It is in such a background, the domestication translation in order to cater to the tastes of the recipient, always in accordance with the target language specific political, cultural and ideological norms to adjust the target text, had to listen to British and American culture with weak culture, become the tool of the colonists cultural colonization.

In the last ten years, the translation of domestication and foreignization has been the beginning of the "naturalization of translation", which was published in modern foreign language in 1987. However, the author may not have expected that foreignization and domestication would be widely discussed as a new theoretical category. The terminology of domestication and foreignization discussed by western scholars is not complementary, but mutually exclusive. American scholar Venuti in discussing alienation translation strategy of domestication translation made description: abide by the target language culture of the current mainstream values, openly the assimilation of the conservative of the original method, so as to make the translation conform to the local standard of the law, publishing trends and political needs. The biggest characteristic of domestication translation is to use fluent idiomatic English translation, in this kind of translation, translators efforts concealed by fluent translation, the translator is invisible, hidden the differences between different cultures, the target language replaced the target language cultural values of the mainstream culture, the strangeness of the original has been played down, translation and become more transparent. The foreignization translation strategy from the post-colonial theory is regarded as the colonization and the collusion of imperialism and the manifestation of cultural hegemonism. Therefore, Venuti advocates the translation strategy of alienation. According to this strategy, translators and interpreters strive to break away from a strong culture in the process of translation. The translation of foreignization should not be interpreted as the corresponding translation, and it cannot improve the fidelity of the translation. Postcolonial scholars Robinson thinks that alienation translation and literal translation and word-for-word translation, just not as extreme as, because they do not adhere to adhere to the original in translation the meaning of individual words in a sequence of syntax, but insisted that retains the original. In the translation of foreignization, new things may be added, thus achieving the status of the translator, improving the status of translation, and making a forceful return on the cultural hegemony of translation.

It can be seen that the domestication/foreignization of western scholars is two opposing concepts in political ideology, and in the two extremes of discourse rights, there is no reconciliation or compromise. This is markedly different from the literal translation of the previous discussion. But much of the discussion is treated as a concept of equivalence, which can lead to theoretical misunderstandings and practical confusion.

\section{Two. The domestication and foreignization in Chinese}

How wide is the connotation of alienation and domestication in English and Chinese? This is something we should be aware of when we study and discuss domestication/foreignization and literal translation. The English expression of domestication/foreignization is the domesticating/foreignizing translation. Although it has some similarities with the free translation/literal translation we are discussing today, there are obvious differences in its nature. The former is the method, and the latter is the result, and if we say the same, we will describe the result. Naturalization/alienation and translation are two distinct categories, like two circles, with only a small number of overlapping edges. The results of foreignization/domestication cannot be described in form and likeness. Alienation and naturalization are a strategy, and in practice, such methods as literal translation, translation, and interpretation may be adopted. As a pair of proprietary translation 
terms, Foreignizing translation/domesticating translation is only elaborated in the latest English academic works. And free translation/literal translation is not. "See a translation is alienation translation or domestication translation, depends entirely on cultural reconstruction, in the form of translation in this form with the production and marketing; what alienation or domestication is only considering to change the value of the target language culture can be defined."

"Current on the understanding of" domestication "problem, should distinguish between domestication translation colleagues method of two premises: one is the faithful principle under domestication, the second is the premise of domestication. The former is generally the stipulation, the latter is descriptive; the former is the primitive splitting, the latter is the target language and the target language culture orientation." This distinction is basically right. However, we can also make a distinction between the nature of the translation: the naturalization of the faithful principle is a linguistic one, and it is the artistic effect of translation, which is the method of translation; The naturalization of non-fidelity is the cultural level, which is concerned with the ideology of translation and is a translation strategy. So far we discussed there are two different types of foreignization and domestication translation study, the first is a Venuti terms, has been mentioned before, the other is some China's repeated use of naturalization/alienation, the author in English assimilation (adaptation) and the adaptation to refer to them. The translation of foreignization and domestication is the reflection of culture, and its influence on literature and even culture from the ideology of translation belongs to literary criticism and philosophical category. The application of the dissimilation of the deconstruction meaning of post-colonial to the translation is a matter of recent years, which is reflected in the translation practice, which is mainly embodied in the literary translation in the form of written symbols. At the same time, the traditional sense of alienation and domestication and foreignization and domestication in the modern sense has different functions and purposes, in Chinese, use the same words to represent them, but, in the English language level is with the assimilation of foreignizing and domesticating translation (adaptation)/alienation to express, and cultural aspects of alienation and domestication is expressed by domesticating/foreignzing. , of course, also can like dealing with culture is a word, with the first letter uppercase Domesticating/Foreignzing to refer to as a cultural strategy of domestication and foreignization, with the first letters lowercase of Domesticating/foreignizing to refer to today's cultural translation. The domestication and foreignization of lower case letters are the extension and development of the translation and literal translation, and capital letters domestication and foreignization are the revolution of free translation and literal translation, which opens up new areas of translation research.

\section{Third. The theory and practice of domestication and foreignization}

Domestic scholars have discussed the phenomenon of domestication and foreignization and the equivalent of literal translation and free translation. Mr. Ge has a precondition for discussing the concept of the pair, which is to put aside the present context of domestication/alienation, and is based on the literal meaning. The two translation tendencies of domestication and foreignization have often clashed with each other since their own translation. In the 20th century, there was a dispute about the westernization and naturalization of lu xun's "hard translation". Before this, yan fu, Lin shu, Liang qichao and so on, can be regarded as the translation of naturalization. "Lu xun's rigid translation and his translation thoughts are for him 'against feudalism, reforming citizens' concept. But $\mathrm{Lu}$ xun's intention to incur the misreading,' hard translation 'initiative and eventually drown in the din of domestication theory. Later, fu lei's theory of" spirit likeness ", said Qian zhongshu's "being" is an extension of the theory of naturalization. Visible, the discussion of domestication and foreignization are often prevail domestication theory, although everyone agree to preserve the foreign flavor." The ge is a new round of domestication/foreignization. Because in this discussion of alienation/domestication, people almost "overwhelmingly believe that translation should promote alienation".

Objectively speaking, it is not unreasonable to give a reminder. But Mr. Ge reminds China of the problem of domestication and foreignization, and should be treated dialectically. Some scholars in 
the response of naturalization/alienation translation proposed by western scholars advocate at the same time, improve the European translation which was advocated by lu xun and liang shiqiu and others denounce the status of "hard translation". Lu xun had hoped that the translation could convey new ideas and introduce new forms of expression for Chinese language, so as to bring new blood to Chinese culture and bring new vitality. Unfortunately, in the last century, domestication/foreignization has tended to prevail. Although we can't exclude the misreading in theory, some scholars today that they want to Venuti etc. Western scholars point of view, but in practice, but it has not been well implemented, but their appeal and practice created the alienation/literal translation of unprecedented good situation, make the translation studies from the past language level to rise to the level of culture, literal translation method has been widely recognized.

Therefore, People should treat this problem didactically. First of all, there should be more referrals to western domestication and foreignization translation strategies. If the theory is to be tasted, the feasibility of translation studies will be greatly reduced. Second, in the language and culture level of alienation/naturalization discussion is acceptable, but these studies should not be profiling, with a mask, put some example, to write the article, in so doing, will undoubtedly reduce the academic status of translation studies. Third, with the strategy of foreignization and domestication can discuss how to translation theory and practice of combining tighter some, this may be an important topic in the study of translation theory construction, we should not only consider from the traditional translation theory, but also from the interdisciplinary perspective to consider the theoretical construction of translation, but so, translation studies can we constantly keep vitality.

\section{Conclusion}

The translation strategies of foreignization and domestication discussion without end, will continue, the researchers should begin from the cross-cultural perspective to think about the problem of foreignization and domestication, in this way, it can fully reflect the influence of. It is certain that this discussion, not only for translation studies, will have positive influence on cultural anthropology, sociology, comparative literature, etc.

\section{Reference}

[1]. The Basset, Susan \& Andre Lever. 2001. Constructing Cultures: Essays on Literary Translation. Shanghai Foreign Education Press.

[2].In the middle of the world, there is a question on the part of the world.

[3]. Doppler, Cay. 1993. Inter-lingual transfer and issues. Perspectives: Studies in Translation. 1993:2, Museum Musculature Press.

[4]. Northcott, w. h. 1984. Oral English: Principles and Practices. Rafael, Burton. The Art of Translating Poetry. The Pennsylvania State University Press. A. the Communication Between the two Cultures Research Press.

[5]. Snell-horn - by, Mary. 2001. Translation Studies: An Integrated Approach. Shanghai Foreign

Education Press.

[6]. Steiner, George. 1975. After Babel: Aspects of Language and Translation. Oxford University Press.

[7] Tory, Gideon. 2001.Press.

[8]. Gao Xuedong, 2000, literature and Chinese literary tradition, Shandong university press.

[9]. Goo jianzhong, 1998, cultural factors in translation: foreignization and domestication, foreign 
languages (2)

[10]. Hun gongze, 1994, evolution and development of translation theory, Taipei: shun Lin publishing co., LTD. 